\title{
Structural laterality is associated with cognitive and mood outcomes: An assessment of 105 healthy aged volunteers
}

\author{
M. Esteves ${ }^{\mathrm{a}, \mathrm{b}, \mathrm{c}}$, P. Marques ${ }^{\mathrm{a}, \mathrm{b}, \mathrm{c}}$, R. Magalhães ${ }^{\mathrm{a}, \mathrm{b}, \mathrm{c}}$, T.C. Castanho ${ }^{\mathrm{a}, \mathrm{b}, \mathrm{c}}$, J.M. Soares $^{\mathrm{a}, \mathrm{b}, \mathrm{c}}$, \\ A. Almeida ${ }^{\mathrm{a}, \mathrm{b}, \mathrm{c}}$, N.C. Santos ${ }^{\mathrm{a}, \mathrm{b}, \mathrm{c}}$, N. Sousa ${ }^{\mathrm{a}, \mathrm{b}, \mathrm{c}}$, H. Leite-Almeida ${ }^{\mathrm{a}, \mathrm{b}, \mathrm{c}, *}$

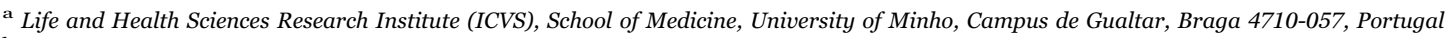 \\ b ICVS/3B's - PT Government Associate Laboratory, Braga/Guimarães, Portugal \\ c Clinical Academic Center - Braga, Braga, Portugal
}

\section{A R T I C L E I N F O}

Keywords:

Aging

Cognition

Mood

Laterality

MRI

\begin{abstract}
A B S T R A C T
The human brain presents multiple asymmetries that dynamically change throughout life. These phenomena have been associated with cognitive impairments and psychiatric disorders although possible associations with specific patterns of cognitive aging are yet to be determined. We have therefore mapped and quantified morphological asymmetries in a heterogeneous and aged population (65.2 \pm 8.0 years old, 52 male and 53 female) to explore potential associations between the asymmetries in specific brain regions and cognitive performance. The sample was characterized in a battery of neuropsychological tests and in terms of brain structural asymmetries using a ROI-based approach. A substantial number of brain areas presented some degree of asymmetry. Such biases survived a stringent statistical correction and were largely confirmed in a voxel-based analysis. In specific brain areas, like the thalamus and insula, asymmetry was correlated with cognition and mood descriptors as the Stroop words/colors test or depressive mood scale, respectively. Curiously in the latter, the association was independent of its left/right direction. Altogether, results reveal that asymmetry is widespread in the aged brain and that area-specific biases (degree and direction) associate with the functional profile of the individual.
\end{abstract}

\section{Introduction}

The human brain is remarkably asymmetrical and gross distortions of brain symmetry like the Yakovlevian (anticlockwise) torque and the petalia have been recognized for decades (Galaburda et al., 1978; Hugdahl, 2011; Rogers, 2014; Sun and Walsh, 2006; Toga and Thompson, 2003). At the volumetric and cytoarchitectural levels, prominent asymmetries have been reported. A classic example is the marked leftward increase of the planum temporale in most individuals (Lyttelton et al., 2009; Takao et al., 2011; Watkins et al., 2001), while more recent subcortical asymmetries such as the leftward asymmetry of the habenula have been described (Ahumada-Galleguillos et al., In press). Left/right side differences in columnar organization (packing) (Chance et al., 2013) as well as in neuronal morphology (Scheibel et al., 1985) - size and dendritic arborization - have also been demonstrated. Dopamine (Glick et al., 1982) and noradrenaline (Oke et al., 1978) abundance is left and rightward lateralized respectively and marked differences in the expression of opioid receptors and respective ligands between the left and right anterior cingulate cortex were recently shown (Watanabe et al., 2015).

Some structural asymmetries seem to have a functional role. For example, the structural leftward imbalance of the planum temporale has been shown to be increased in musicians with perfect pitch (Keenan et al., 2001) and functional leftward asymmetry for language has been extensively described (see Toga and Thompson (2003)) for review). Moreover, a relevant body of literature describes abnormal structural lateralization associated with neuropsychiatric diseases. For example, right/left caudate volume quotient has been correlated with the manifestation of attention deficit and hyperactivity disorder (ADHD)-like symptoms in healthy subjects (Dang et al., 2016) and Eden et al. (2015) have shown an association between left or right prefrontal white matter pathways and reappraisal or trait anxiety, respectively. Brain asymmetries (or its lack) have also been recognized in obsessive-compulsive disorder (OCD) (Peng et al., 2015), autism (Conti et al., 2016; Herbert et al., 2005) and schizophrenia (Miyata et al., 2012; Narr et al., 2001; Park et al., 2013; Sun et al., 2015) - see also for review (Lindell and Hudry, 2013; Oertel-Knochel and Linden, 2011; Ribolsi et al., 2014; Ribolsi et al., 2009) - suggesting that

\footnotetext{
* Corresponding author at: Life and Health Sciences Research Institute (ICVS), School of Medicine, University of Minho, Campus de Gualtar, Braga 4710-057, Portugal

E-mail address: hugoalmeida@med.uminho.pt (H. Leite-Almeida).
} 
asymmetry is crucial for (or at least reflects) proper functioning (Concha et al., 2012). Indeed, morphological asymmetries manifest early in development (Concha et al., 2012; Kasprian et al., 2011; Song et al., 2015) and seem to increase throughout life (Plessen et al., 2014; Zhou et al., 2013). However, while age-induced functional asymmetry changes seem to be associated with preservation of cognitive function as shown by models such as HAROLD (Cabeza et al., 2002) or CRUNCH (Reuter-Lorenz and Cappell, 2008), the association between the dynamic nature of structural laterality and the course of emotional and cognitive faculties throughout healthy aging is not entirely understood. In fact, the healthy aged population has not even been characterized in terms of hemispheric structural asymmetries.

We thus hypothesized that the older brain presents a high number of asymmetrical areas, which should be increased in comparison with younger subjects. Moreover, we hypothesized that many of these asymmetries should be relevant for neuropsychological profiles. In order to achieve these goals, we studied structural laterality in a thoroughly characterized and heterogeneous population of aged individuals and correlated these data with cognitive performance and mood classification.

\section{Methods}

\section{Ethics statement}

This study was performed in accordance with the Declaration of Helsinki (59th amendment) and approved by national and local ethics review boards (Comissão Nacional de Protecção de Dados, Hospital de Braga, Centro Hospitalar do Alto Ave and Unidade Local de Saúde do Alto Minho). All volunteers signed informed consent and all medical and research professionals who had access to participants' identity signed a Statement of Responsibility and Confidentiality.

\section{Subjects}

The population from the Switchbox project, a project that aims to study healthy aging in the population of northern Portugal, was used in the present study. Subjects' recruitment was performed in two phases. Initially, a large sample, representative of the older Portuguese population in terms of sex and education, was cognitively characterized [n=1051 after inclusion/exclusion criteria; subjects were randomly selected from the Guimarães and Vizela local area health authority registries (Costa et al., 2013; Santos et al., 2013, 2014)]. Then, in a second-phase, and based on the neurocognitive assessment, 120 subjects were selected from the previous sample in order to provide cognitive profiles of overall good cognitive performance $(n=60)$ and overall poor performance $(n=60)$ for further characterization, including magnetic resonance imaging (MRI) screening. Further details regarding formation of the groups are presented as Supplementary data.

Inability to understand the informed consent, participant's choice to withdraw from the study, incapacity and/or inability to attend the MRI session, dementia and/or diagnosed neuropsychiatric and/or neurodegenerative disorder (medical records) were the primary exclusion criteria. Regarding cognitive impairment, adjusted thresholds for the Mini-Mental State Examination (MMSE) test were calculated and applied, accounting for age and/or education (Busch and Chapin, 2008; Grigoletto et al., 1999). Following the MMSE validation for the Portuguese population (Guerreiro et al., 1994) the following thresholds were used: MMSE score $<17$ if individual with $\leq 4$ years of formal school education and/or $\geq 72$ years of age, and MMSE score $<23$ otherwise.

From the 120 subjects recruited for the Switchbox project, nine refused to perform the MRI screening in the assessment day, four had brain lesions/pathology detected through the MRI and two presented excessive motion/artifacts. This resulted in a final sample of 105
Table 1

Population characterization. Distribution of the population included in the global analysis and respective cognitive and mood scores.

\begin{tabular}{lll}
\hline & Female & Male \\
\hline Number of subjects & 53 & 52 \\
Age & $66.5 \pm 7.7(51$ to 82$)$ & $63.8 \pm 8.1$ (51 to 79$)$ \\
Years of formal education & $4.1 \pm 2.8$ & $6.7 \pm 4.2$ \\
SRT-CLTR & $14.0 \pm 12.3$ & $18.1 \pm 12.7$ \\
SRT-DR & $4.9 \pm 3.2$ & $5.8 \pm 2.9$ \\
SRT-int & $2.8 \pm 4.4$ & $2.1 \pm 2.5$ \\
Dforward & $7.2 \pm 2.0$ & $8.2 \pm 2.4$ \\
Dbackward & $3.8 \pm 2.3$ & $5.0 \pm 2.7$ \\
Stroop-w & $56.8 \pm 19.8$ & $71.6 \pm 20.0$ \\
Stroop-c & $46.6 \pm 13.8$ & $50.5 \pm 15.2$ \\
Stroop-wc & $26.1 \pm 9.9$ & $32.1 \pm 14.2$ \\
FAS & $14.7 \pm 9.4$ & $21.1 \pm 12.8$ \\
GDS & $13.2 \pm 6.3$ & $8.8 \pm 6.3$ \\
\hline
\end{tabular}

participants (description in Table 1 and Supplementay Table 1). All volunteers were right-handed.

\section{Cognitive and mood assessment}

Cognitive and mood evaluation was performed by a team of trained psychologists and all tests have been previously described (Santos et al., 2014). The Selective Reminding Test (SRT) (Buschke et al., 1995) was used as a verbal learning and memory test and evaluated the following components: consistent long term retrieval (CLTR), long term storage, delayed recall (DR) and intrusions. The Digits Span Test (Wechsler, 1997) was used in the forward (dforward) and reverse (dbackward) order as a measure of attention in the first case and working memory/executive function in the second. The Stroop test (Strauss et al., 2006), which is divided into three modules - words (w), colors (c) and words/colors (wc) - assessed selective attention, cognitive flexibility and response inhibition. Verbal fluency was evaluated through the Controlled Oral Word Association F-A-S (FAS) (Lezak et al., 2004) test, while depressive mood was assessed using the Geriatric Depression Scale (GDS) (Yesavage et al., 1982).

\section{Image acquisition}

Acquisitions were performed on a clinically approved Siemens MagnetomAvanto $1.5 \mathrm{~T}$ (Siemens Medical Solutions, Elangen, Germany) scanner, in Hospital de Braga, using a 12-channel receiveonly Siemens head coil. A T1-weighted magnetization-prepared rapid gradient echo (MPRAGE) sequence with repetition time $(\mathrm{TR})=2730$ $\mathrm{ms}$, echo time $(\mathrm{TE})=3.5 \mathrm{~ms}$, flip angle $=7^{\circ}$, field of view $(\mathrm{FoV})=256$. $256 \mathrm{~mm}, 176$ sagittal slices, with isotropic resolution of $1 \mathrm{~mm}$ and no slice-gap was used.

\section{ROI-based volumetric analysis}

For the region-of-interest (ROI) based volumetric analysis, the structural data was processed with the semi-automated workflow implemented in FreeSurfer v5.10 (http://surfer.nmr.mgh.harvard. edu/). This pipeline implements a total of 31 processing steps which include the spatial normalization to Talairach standard space, skull stripping, intensity normalization, tessellation of gray matter (GM)white matter (WM) boundary and segmentation of cortical, subcortical and WM regions. Results obtained with this pipeline were shown to be reliable across sessions, scanner platforms, updates, and field strengths (Jovicich et al., 2009) and were validated against manual segmentations (Fischl et al., 2002). Details regarding the procedures and improvements implemented throughout the years have been described in several publications (Desikan et al., 2006; Destrieux et al., 2010; Fischl et al., 2002). For the present work only volumes 
resulting from the subcortical and cortical segmentation according to the Desikan atlas were considered (Desikan et al., 2006). ROI-wise measures of cortical thickness and surface area were not considered in order to facilitate the comparison between ROI-wise and voxel-wise laterality assessed with different techniques.

Laterality Index (LI) for structural segmentation-derived data was calculated using the following formula in an intra-individual analysis:

$\mathrm{LI}=(\mathrm{L}-\mathrm{R}) /(\mathrm{L}+\mathrm{R})$

where $\mathrm{L}=$ volume of the specified left region and $\mathrm{R}=$ volume of the specified right region. The absolute value of this result was used to determine the effects of side-independent asymmetries, i.e. the asymmetry index (AI).

\section{VBM analysis}

In order to control for possible atlas-derived biases, a complementary voxel-wise analysis was also performed using a modified version of the typical voxel based morphometry (VBM) analysis. The key aspect of the analysis is inter-hemispheric correspondence. In order to achieve this, we applied the typical VBM data processing pipeline (Mechelli et al., 2005) using two versions of the structural scans for each participant: a regular version of the structural scan and a flipped version in which the original scan was flipped along the midsagittal plane. All the VBM procedures were performed using Statistical Parametric Mapping 8 (SPM8; http://www.fil.ion.ucl.ac.uk/spm/). Initially all images (flipped and unflipped versions) were segmented into six different tissue classes (GM, WM, cerebrospinal fluid, skull, soft tissue and others) using the New Segmentation procedure. Then, the Diffeomorphic Anatomical Registration Through Exponentiated Lie Algebra (DARTEL) procedure was used in order to create a study specific template, which, by using both flipped and unflipped versions of the structural scans, originated a symmetric template. The GM tissue maps were then affine registered to the Montreal Neurological Institute (MNI) standard space for localization purposes. The GM maps were then scaled with the Jacobian determinants, also known as modulation, so tissue volumes could be compared and smoothed with a $10 \mathrm{~mm}$ fullwidth at half-maximum (FWHM) Gaussian filter.

LI images were created using imcalc from SPM8 according to the following formula:

$\mathrm{LI}=\left(\operatorname{Im}_{\text {unflipped }}-\operatorname{Im}_{\text {flipped }}\right) /\left(\operatorname{Im}_{\text {unflipped }}+\operatorname{Im}_{\text {flipped }}\right)$

where $\operatorname{Im}_{\text {unflipped }}=$ unflipped image and $\operatorname{Im}_{\text {flipped }}=$ image flipped in the midsagittal plane. According to this formula, positive voxels in the left hemisphere of the brain reflect greater volumes on the left hemisphere and vice-versa for positive voxels in the right hemisphere.

\section{Statistical analysis}

All statistical analysis was performed on Matlab R2009b software. $\mathrm{P}<0.05$ was considered the threshold for statistical significance (Bonferroni-Holm correction was applied whenever multiple comparisons were performed (Holm, 1979)). Graphs were attained using Prism 6 software and, except for ROI-based laterality, only significant results are shown. Laterality pictogram was attained using 3D slicer (http://www.slicer.org) (Fedorov et al., 2012).

For ROI-based laterality evaluation values are presented as mean \pm standard error of the mean and as normal distribution of the LI values could not be confirmed, non-parametric tests were used. Variables used for multiple regressions control are shown in the individual analyses.

Statistical analyses of VBM LI images were performed using SPM8. One sample $T$-Tests were performed and results were considered significant at $\mathrm{p}<0.05$ family-wise error (FWE) corrected at the voxel level and cluster size greater than five voxels. In the analysis, an explicit mask was applied by thresholding the gray matter tissue probability map suing a threshold of 0.2 in order to exclude voxels with low probability of corresponding to gray matter.

For determination of the factors that influence structural laterality, multiple linear regressions were conducted, in which the dependent variable was the ROI's LI and independent variables of interest were sex, age, group (good or poor performer) and education.

Multiple regression analyses were also used to determine the association between laterality-related data (LI or AI). The dependent variable was cognitive or mood score and variables of interest were either LI or AI and their interactions with sex or education. These analyses were controlled for sex, age, group and education.

In order to determine if the associations between the LI and the cognitive data were in fact due to the left/right balance or to the single left or right area volumes, a new analysis was run for each significant LI-cognition correlation. All model variables were similar, but LI was replaced with left or right area volume (percentage of intracranial volume, ICV) as independent variables of interest. As only areas of interest were analyzed, presented p-values were not corrected for multiple comparisons.

\section{Results}

\section{Structural asymmetries - ROI-based analysis}

Cortical GM segmentation revealed ubiquitous asymmetries. This lateralization was seen in both directions (left and right) with no obvious left or rightward trends in neighboring areas (Table 2 and Fig. 1). On the temporal lobe, leftward asymmetries were found in the entorhinal and transverse temporal cortices, parahippocampal and superior temporal gyruses and in the temporal pole; the middle temporal gyrus was the sole temporal area presenting a rightward volumetric asymmetry. Frontally, leftward asymmetries were seen in the superior frontal and caudal middle frontal gyri, pars opercularis and lateral and medial orbitofrontal cortices, contrasting with the rightward lateralization found in the rostral middle frontal gyrus, pars triangularis, pars orbitalis, frontal pole and paracentral lobule. Laterality in the parietal lobe was well distributed with two areas presenting $\mathrm{L}>\mathrm{R}$ bias (postcentral and supramarginal gyruses) and two others presenting $\mathrm{R}>\mathrm{L}$ asymmetry (inferior parietal and precuneus cortices). Rostral anterior and isthmus cingulate cortices were found to be left lateralized and the insula presented a rightward asymmetry. The only two occipital asymmetrical areas were the pericalcarine cortex and the lingual gyrus, both showing right lateralization.

Similarly, subcortical areas showed significant lateralization (Table 2 and Fig. 1). Lateral ventricle, accumbens, pallidum and putamen showed a leftward bias while the hippocampus, caudate and amygdala presented rightward lateralization. Interestingly, average LIs over the entire cortical gray, white matter and sub-cortical areas (Table 2 and Fig. 1) presented rightward laterality, even though only average gray matter LI reached statistical significance.

\section{Structural asymmetries - VBM-based analysis}

Aiming to provide validation to our ROI-based approach, VBM analysis of left and right gray matter differences was performed (Fig. 2). Leftward asymmetries were found in rolandic operculum, supramarginal gyrus, Heschl gyrus, inferior occipital, middle occipital, paracentral lobule, parahippocampus and fusiform gyrus. Rightward structural lateralization was found in calcarine, parahippocampus, middle frontal gyrus, middle temporal gyrus, inferior parietal gyrus, orbital part of the inferior frontal gyrus, supramarginal gyrus and fusiform gyrus. In order to facilitate comparisons, an Automatic Anatomical Labeling (AAL) - FreeSurfer (Desikan Atlas) correspondence was established. Left lateralized areas corresponded to supramarginal gyrus, superior temporal gyrus, lateral occipital cortex, precentral gyrus, parahippocampal gyrus and fusiform gyrus. Rightward shifts were found in cuneus cortex, entorhinal cortex, rostral 
Table 2

Laterality statistics. Statistics for cortical gray matter, subcortical and general areas' LI. ROI=Region of Interest, LI=laterality index, corrected p-value=Bonferroni corrected p-value for 46 comparisons.

\begin{tabular}{|c|c|c|c|c|c|}
\hline ROI & Mean LI & $\begin{array}{l}\text { Standard } \\
\text { Deviation }\end{array}$ & $\begin{array}{l}\text { Corrected } \\
\text { p-value }\end{array}$ & z-value & $\begin{array}{l}\text { r (effect } \\
\text { size) }\end{array}$ \\
\hline \multicolumn{6}{|l|}{ Cortical Gray Matter } \\
\hline $\begin{array}{l}\text { Rostral Anterior } \\
\text { Cingulate }\end{array}$ & 0.1262 & 0.0951 & $<0.0001$ & 8.2789 & 0.8118 \\
\hline $\begin{array}{l}\text { Transverse } \\
\text { Temporal Cortex }\end{array}$ & 0.1253 & 0.0952 & $<0.0001$ & 8.2526 & 0.8054 \\
\hline Pars Opercularis & 0.0909 & 0.0815 & $<0.0001$ & 7.7730 & 0.7586 \\
\hline Isthmus Cingulate & 0.0514 & 0.0704 & $<0.0001$ & 6.4013 & 0.6277 \\
\hline $\begin{array}{l}\text { Caudal Middle } \\
\text { Frontal Gyrus }\end{array}$ & 0.0414 & 0.0709 & $<0.0001$ & 5.1009 & 0.5002 \\
\hline Entorhinal Cortex & 0.0333 & 0.0844 & 0.0043 & 3.6741 & 0.3603 \\
\hline $\begin{array}{l}\text { Parahippocampal } \\
\text { Gyrus }\end{array}$ & 0.0332 & 0.0658 & 0.0001 & 4.5794 & 0.4469 \\
\hline $\begin{array}{l}\text { Supramarginal } \\
\text { Gyrus }\end{array}$ & 0.0304 & 0.0498 & $<0.0001$ & 5.4155 & 0.5310 \\
\hline Temporal Pole & 0.0245 & 0.0678 & 0.0107 & 3.4030 & 0.3321 \\
\hline $\begin{array}{l}\text { Banks of the } \\
\text { Superior Temporal } \\
\text { Sulcus }\end{array}$ & 0.0239 & 0.0831 & 0.1187 & 2.6072 & 0.2557 \\
\hline $\begin{array}{l}\text { Superior Temporal } \\
\text { Gyrus }\end{array}$ & 0.0235 & 0.0413 & $<0.0001$ & 4.9809 & 0.4908 \\
\hline $\begin{array}{l}\text { Medial Orbitofrontal } \\
\text { Cortex }\end{array}$ & 0.0201 & 0.0531 & 0.0072 & 3.5245 & 0.3440 \\
\hline Postcentral Gyrus & 0.0199 & 0.0489 & 0.0038 & 3.7163 & 0.3644 \\
\hline $\begin{array}{l}\text { Superior Frontal } \\
\text { Gyrus }\end{array}$ & 0.0190 & 0.0315 & $<0.0001$ & 5.3659 & 0.5287 \\
\hline $\begin{array}{l}\text { Lateral Orbitofrontal } \\
\text { Cortex }\end{array}$ & 0.0147 & 0.0338 & 0.0020 & 3.9081 & 0.3814 \\
\hline Fusiform Gyrus & 0.0108 & 0.0562 & 0.5935 & 1.7854 & 0.1742 \\
\hline Precentral Gyrus & 0.0077 & 0.0309 & 0.2142 & 2.3687 & 0.2334 \\
\hline $\begin{array}{l}\text { Inferior Temporal } \\
\text { Gyrus }\end{array}$ & 0.0076 & 0.0568 & 1.1036 & 1.2228 & 0.1193 \\
\hline $\begin{array}{l}\text { Superior Parietal } \\
\text { Cortex }\end{array}$ & 0.0021 & 0.0419 & 1.0224 & 0.6569 & 0.0641 \\
\hline Posterior Cingulate & -0.0031 & 0.0693 & 1.0224 & 0.5383 & 0.0528 \\
\hline $\begin{array}{l}\text { Lateral Occipital } \\
\text { Cortex }\end{array}$ & -0.0072 & 0.0472 & 0.8857 & 1.1966 & 0.1173 \\
\hline Cuneus Cortex & -0.0100 & 0.0566 & 1.0286 & 1.4504 & 0.1436 \\
\hline Precuneus Cortex & -0.0137 & 0.0287 & 0.0005 & 4.2675 & 0.4185 \\
\hline Lingual Gyrus & -0.0172 & 0.0490 & 0.0230 & 3.1682 & 0.3107 \\
\hline Insula & -0.0177 & 0.0385 & 0.0007 & 4.1638 & 0.4063 \\
\hline $\begin{array}{l}\text { Rostral Middle } \\
\text { Frontal Gyrus }\end{array}$ & -0.0244 & 0.0427 & $<0.0001$ & 5.1485 & 0.5024 \\
\hline $\begin{array}{l}\text { Caudal Anterior } \\
\text { Cingulate }\end{array}$ & -0.0334 & 0.1459 & 0.2447 & 2.2585 & 0.2204 \\
\hline $\begin{array}{l}\text { Middle Temporal } \\
\text { Gyrus }\end{array}$ & -0.0491 & 0.0473 & $<0.0001$ & 7.4780 & 0.7368 \\
\hline Pericalcarine Cortex & -0.0545 & 0.0461 & $<0.0001$ & 7.7396 & 0.7663 \\
\hline Paracentral Lobule & -0.0581 & 0.0659 & $<0.0001$ & 6.8747 & 0.6709 \\
\hline Pars Triangularis & -0.0779 & 0.0788 & $<0.0001$ & 7.4310 & 0.7252 \\
\hline $\begin{array}{l}\text { Inferior Parietal } \\
\text { Cortex }\end{array}$ & -0.0902 & 0.0512 & $<0.0001$ & 8.7394 & 0.8570 \\
\hline Pars Orbitalis & -0.1034 & 0.0740 & $<0.0001$ & 8.3859 & 0.8223 \\
\hline Frontal Pole & -0.1472 & 0.0921 & $<0.0001$ & 8.6170 & 0.8409 \\
\hline \multicolumn{6}{|l|}{ Subcortical } \\
\hline Lateral Ventricle & 0.0559 & 0.0885 & $<0.0001$ & 5.6101 & 0.5501 \\
\hline Accumbens & 0.0467 & 0.0959 & 0.0002 & 4.5219 & 0.4413 \\
\hline $\begin{array}{l}\text { Inferior Lateral } \\
\text { Ventricle }\end{array}$ & 0.0331 & 0.1984 & 0.2447 & 2.2862 & 0.2242 \\
\hline Pallidum & 0.0320 & 0.0548 & $<0.0001$ & 5.2533 & 0.5151 \\
\hline Putamen & 0.0143 & 0.0253 & $<0.0001$ & 5.0854 & 0.5111 \\
\hline Thalamus Proper & -0.0037 & 0.0264 & 1.1762 & 1.2929 & 0.1274 \\
\hline Hippocampus & -0.0088 & 0.0281 & 0.0230 & 3.1649 & 0.3118 \\
\hline Caudate & -0.0250 & 0.0273 & $<0.0001$ & 7.1050 & 0.6967 \\
\hline Amygdala & -0.0282 & 0.0685 & 0.0020 & 3.8979 & 0.3822 \\
\hline \multicolumn{6}{|l|}{ General Areas } \\
\hline White Matter & -0.0014 & 0.0070 & 0.4688 & 1.9424 & 0.1905 \\
\hline Sub-Cortical & -0.0019 & 0.0151 & 1.1762 & 1.2246 & 0.1219 \\
\hline Gray Matter & -0.0023 & 0.0050 & 0.0006 & 4.2156 & 0.4134 \\
\hline
\end{tabular}

middle frontal gyrus, banks of the superior temporal sulcus, middle temporal gyrus, superior temporal gyrus, supramarginal gyrus, pars orbitalis, inferior parietal cortex and fusiform gyrus.

\section{Determining factors for structural laterality}

As can be observed in the error bars shown in Fig. 1A, regional asymmetries were relatively homogeneous within the population. In order to confirm this, models with regional LIs as the dependent variable and sex, age, cognitive performance group (group) and years of formal education as independent variables were established. The only factor that had an influence in the LI was sex and only for the fusiform gyrus $\left(p=0.0011, \beta=-0.0465, R^{2}=0.1379\right)$. In fact, post-hoc analysis showed that females presented increased (leftward) LI when compared to males $(\mathrm{p}=0.0001, \mathrm{t}=4.0401, \mathrm{~d}=0.8001)$.

\section{Correlates of laterality, cognition and mood}

\section{Memory}

Memory, as evaluated by the SRT test in its various components, was associated with area-specific laterality while being strongly influenced by cognitive performance group. SRT-CLTR association with superior frontal gyrus LI was mediated by sex (Supplementary Table 2 $\left.\mathrm{p}=0.0062, \beta=-139.5240, \mathrm{R}^{2}=0.7897\right)$. Post-hoc analysis showed that left lateralization in this area was correlated with better performance in female $\left(p<0.0001, R^{2}=0.4268\right)$, but not in male $(p=0.4281$, $\mathrm{R}^{2}=0.0150$ ) subjects (Fig. 3A). SRT-DR's connection with lateral ventricle's LI was mediated by both sex and education $(\mathrm{p}=0.0203$, $\beta=-21.9812$ and $p=0.0137, \beta=3.4567$, respectively $R^{2}=0.4557 \quad$ Supplementary Table 2). In fact, a strong association between rightward lateralization of this area and increased SRT-DR score can be found for male, but not female subjects (Fig. 3B - p=0.0050, $\mathrm{R}^{2}=0.1653$ and $\mathrm{p}=0.9690, \mathrm{R}^{2}=0.0000$ respectively) and for individuals with lower, but not higher education (Fig. $3 \mathrm{C}-\mathrm{p}=0.0009, \mathrm{R}^{2}=0.1453$ and $\mathrm{p}=0.2300, \mathrm{R}^{2}=0.0678$ respectively).

Dbackward results were mostly correlated with group and age of the subjects and no associations with the LI were found. However, asymmetry of the lateral ventricle and cortical gray matter were linked to this outcome and mediated by education (Supplementary Table 3 $\mathrm{p}=0.0375, \quad \beta=3.3144, \quad \mathrm{R}^{2}=0.5821 \quad$ and $\mathrm{p}=0.0477, \quad \beta=59.8505$, $\mathrm{R}^{2}=0.5491$ respectively). Increased asymmetry of the lateral ventricle was connected with increased score in individuals with superior education (Fig. 3D $-\mathrm{p}<0.0001, \mathrm{R}^{2}=0.5883$ ), although this was not true for lower educated subjects $\left(\mathrm{p}=0.4853, \mathrm{R}^{2}=0.5883\right)$. Post-hoc analysis of the association between gray matter AI and dbackward showed that, in individuals with more years of formal education, increased asymmetry was associated with lower scores, while the opposite was true for lower levels of education (Fig. $3 \mathrm{E}-\mathrm{p}=0.1735$, $\mathrm{R}^{2}=0.02520-4$ years of education and $\mathrm{p}=0.5369, \mathrm{R}^{2}=0.0176$ for $>4$ years of education).

\section{Attention, inhibition and cognitive flexibility}

No associations of laterality/asymmetry with Stroop-w or Stroop-c were found. Stroop-wc, which presents increased cognitive demand and is mostly considered as a test that evaluates attention, inhibition and cognitive flexibility (Strauss et al., 2006) was mostly influenced by group. In the thalamus, a LI-sex association was found to be correlated with increased performance in the Stroop-wc (Supplementary Table 2 - $\mathrm{p}=0.0149, \beta=258.0564, \mathrm{R}^{2}=0.5679$ ). Post-hoc analysis (Fig. 4A) revealed that in male participants, a leftward volumetric lateralization of the thalamus was associated with increased number of named colors ( $\mathrm{p}=0.0020, \mathrm{R}^{2}=0.1977$ ), while no correlation could be found for females $\left(p=0.2445, R^{2}=0.0281\right)$.

Verbal fluency, assessed by the FAS, was associated with posterior 

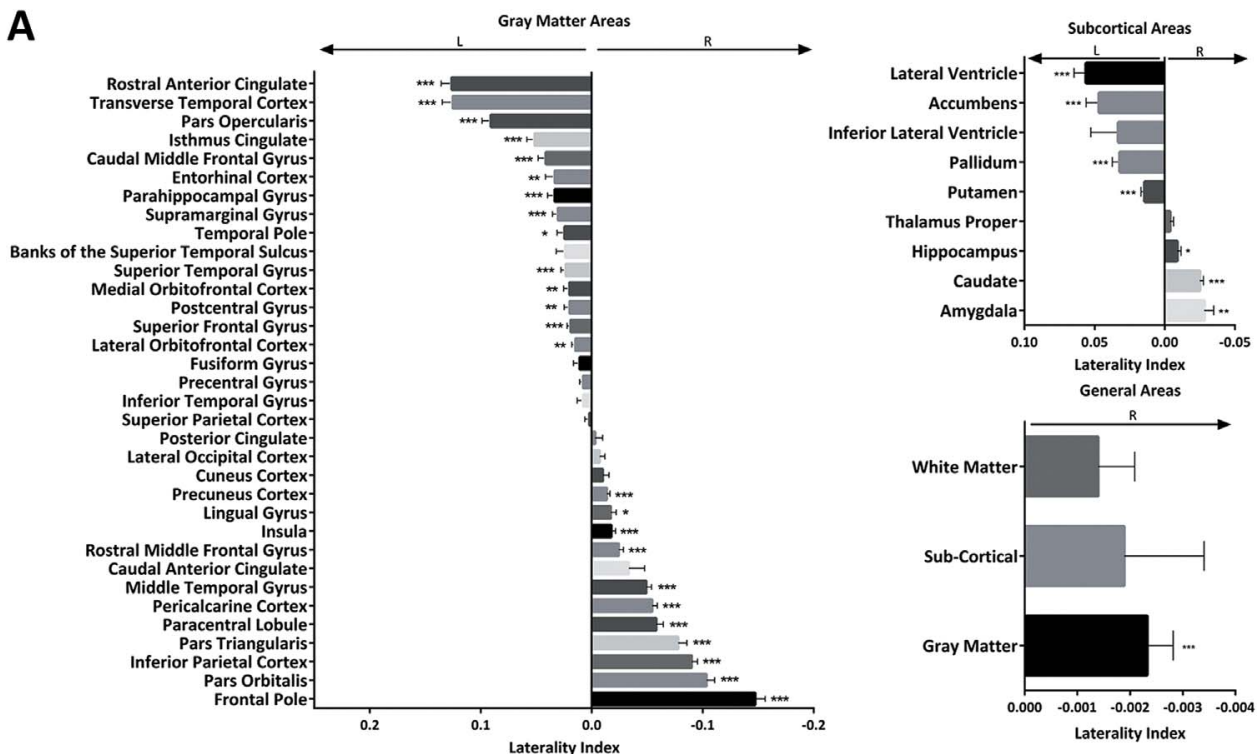

B
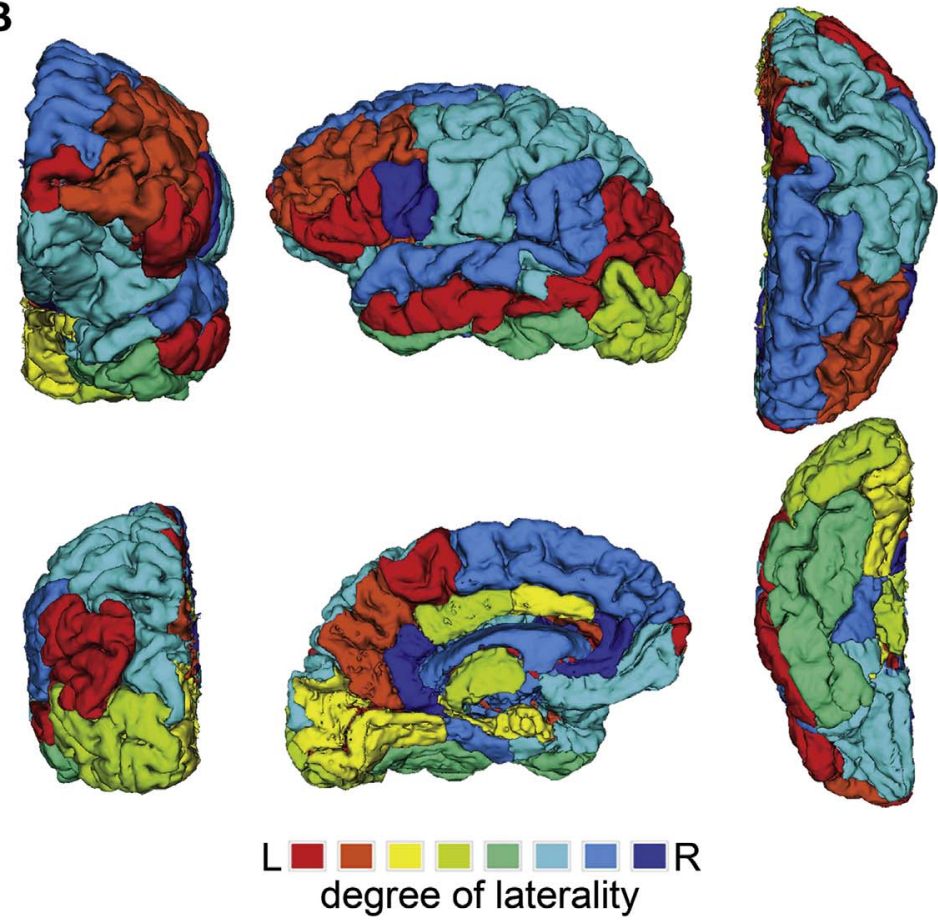

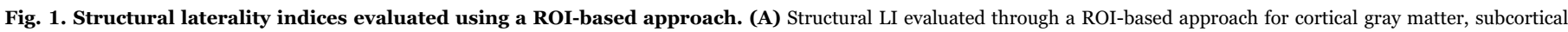

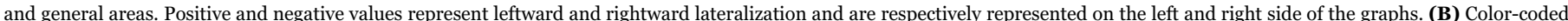

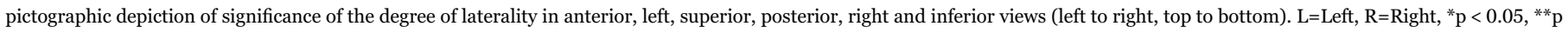
$<0.01,{ }^{* * *} \mathrm{p}<0.001$ in Wilcoxon signed rank analysis Bonferroni corrected for 46 comparisons.

cingulate laterality, but it was mostly influenced by cognitive performance group. Posterior cingulate laterality was correlated with this score in an education-mediated fashion (Supplementary Table 2 $\left.\mathrm{p}=0.0242, \beta=-11.2447, \mathrm{R}^{2}=0.6064\right)$. Interestingly, the association between posterior cingulate LI and performance showed opposite trends in individuals with lower and higher education. In subjects with 0 to $4\left(\mathrm{p}=0.0533, \mathrm{R}^{2}=0.0599\right)$ or more than $4\left(\mathrm{p}=0.0154, \mathrm{R}^{2}=0.2846\right)$ years of formal education, a leftward or a rightward volumetric lateralization of the posterior cingulate are respectively associated with increased number of recalled words (Fig. 4B).

\section{Mood}

Depressive mood was evaluated through the GDS (higher scores are associated with increased depressive symptomatology) and although it was associated with group, the most striking correlation was found between the degree of asymmetry of the insula and the overall score of this scale (Supplementary Table $3-\mathrm{p}=0.0084, \quad \beta=-91.0949$, $\mathrm{R}^{2}=0.3501$ ). Post-hoc analysis confirmed this result by revealing a very strong negative correlation between $\mathrm{AI}$ and GDS score (Fig. $4 \mathrm{C}-\mathrm{p}$ $<0.0001, \mathrm{R}^{2}=0.1477$ ).

\section{Volume-cognition correlates}

The above-described LI-cognition associations could result from either an association between left/right balance and neuropsychological scores or from disproportionate influence of the left or right area. In order to clarify this question, multiple linear regression models were established. 


\begin{tabular}{|c|c|c|c|c|c|c|c|c|c|c|}
\hline \multirow{2}{*}{$\begin{array}{c}\text { cluster } \\
\mathrm{p} \text { (FWE-corr) }\end{array}$} & \multirow{2}{*}{$\begin{array}{l}\text { cluster } \\
\text { size }\end{array}$} & \multirow{2}{*}{$\begin{array}{c}\text { peak } \\
\text { p(FWE-corr) }\end{array}$} & \multirow{2}{*}{ peak T } & \multirow{2}{*}{$z$} & \multicolumn{3}{|c|}{ coordinates } & \multirow{2}{*}{-AAL anatomical region } & \multirow{2}{*}{ Desikan anatomical correpondence } & \multirow{2}{*}{ ROI direction } \\
\hline & & & & & $x$ & $\mathrm{y}$ & 2 & & & \\
\hline \multicolumn{11}{|c|}{ leftward asymmetry } \\
\hline \multirow[t]{3}{*}{0} & 3975 & 0 & 13,56 & Inf & -44 & -30 & 16 & Rolandic Operculum & Supramarginal Gyrus & $L^{* * *}$ \\
\hline & & 0 & 9,63 & Inf & -64 & -27 & 25 & Supramarginal Gyrus & Supramarginal Gyrus & $L^{* * *}$ \\
\hline & & 0 & 8,05 & 7,08 & -64 & -12 & 7 & Heschl Gyrus & Superior Temporal Gyrus & $L^{* *}$ \\
\hline \multirow[t]{2}{*}{0} & 6560 & 0 & 11,07 & Inf & -50 & -73 & -6 & Inferior Occipital & Lateral Occipital Cortex & $R^{N 5}$ \\
\hline & & 0 & 9,96 & Inf & -50 & -76 & 7 & Middle Occipital & Lateral Occipital Cortex & $R^{N 5}$ \\
\hline 0 & 588 & 0 & 8,58 & 7,45 & -9 & -30 & 67 & Paracentral Lobule & Precentral Gyrus & $\mathrm{L}^{\mathrm{NS}}$ \\
\hline \multirow[t]{2}{*}{0} & 350 & 0 & 7,05 & 6,36 & -26 & -33 & -9 & Parahippocampus & Parahippocampal Gyrus & $L^{* * *}$ \\
\hline & & 0 & 6,48 & 5,92 & -27 & -42 & -12 & Fusiform Gyrus & Fusiform Gyrus & $\mathrm{L}^{\mathrm{NS}}$ \\
\hline \multicolumn{11}{|c|}{ rightward asymmetry } \\
\hline \multirow[t]{2}{*}{0} & 9225 & 0 & 13,82 & Inf & 15 & -61 & 12 & Calcarine & Cuneus Cortex & $R^{N S}$ \\
\hline & & 0 & 11,9 & Inf & 22 & -9 & -21 & Parahippocampus & Entorhinal Cortex & $L^{* *}$ \\
\hline \multirow[t]{2}{*}{0} & 2607 & 0 & 8,28 & 7,24 & 40 & 45 & 33 & Middle Frontal Gyrus & Rostral Middle Frontal Gyrus & $\mathrm{R}^{* * * *}$ \\
\hline & & 0 & 7,6 & 6,76 & 27 & 56 & 28 & Middle Frontal Gyrus & Rostral Middle Frontal Gyrus & $R^{* * *}$ \\
\hline \multirow[t]{3}{*}{0} & 626 & 0 & 8,78 & 7,57 & 49 & -37 & 4 & Middle Temporal Gyrus & Banks of the Superior Temporal Sulcus & $\mathrm{L}^{\mathrm{NS}}$ \\
\hline & & 0 & 8,21 & 7,19 & 51 & -28 & -3 & Middle Temporal Gyrus & Middle Temporal Gyrus & $\mathrm{R}^{* * *}$ \\
\hline & & 0 & 7,74 & 6,87 & 52 & -19 & -8 & Middle Temporal Gyrus & Superior Temporal Gyrus & $L^{* *}$ \\
\hline \multirow[t]{2}{*}{0} & 337 & 0 & 7,43 & 6,64 & 57 & -31 & 52 & Inferior Parietal Gyrus & Supramarginal Gyrus & $L^{* * *}$ \\
\hline & & 0,001 & 6,16 & 5,67 & 52 & -42 & 55 & Inferior Parietal Gyrus & Supramarginal Gyrus & $L^{* * *}$ \\
\hline 0 & 178 & 0 & 6,76 & 6,14 & 51 & 20 & -9 & Orbital Part of the Inferior Frontal Gyrus & Pars Orbitalis & $\mathrm{R}^{* * *}$ \\
\hline 0,011 & 28 & 0,006 & 5,78 & 5,37 & 52 & -43 & 40 & Supramarginal Gyrus & Inferior Parietal Cortex & $R^{* * *}$ \\
\hline 0,021 & 12 & 0,023 & 5,43 & 5,09 & 36 & -9 & -41 & Fusiform Gyrus & Fusiform Gyrus & $L^{\mathrm{NS}}$ \\
\hline
\end{tabular}
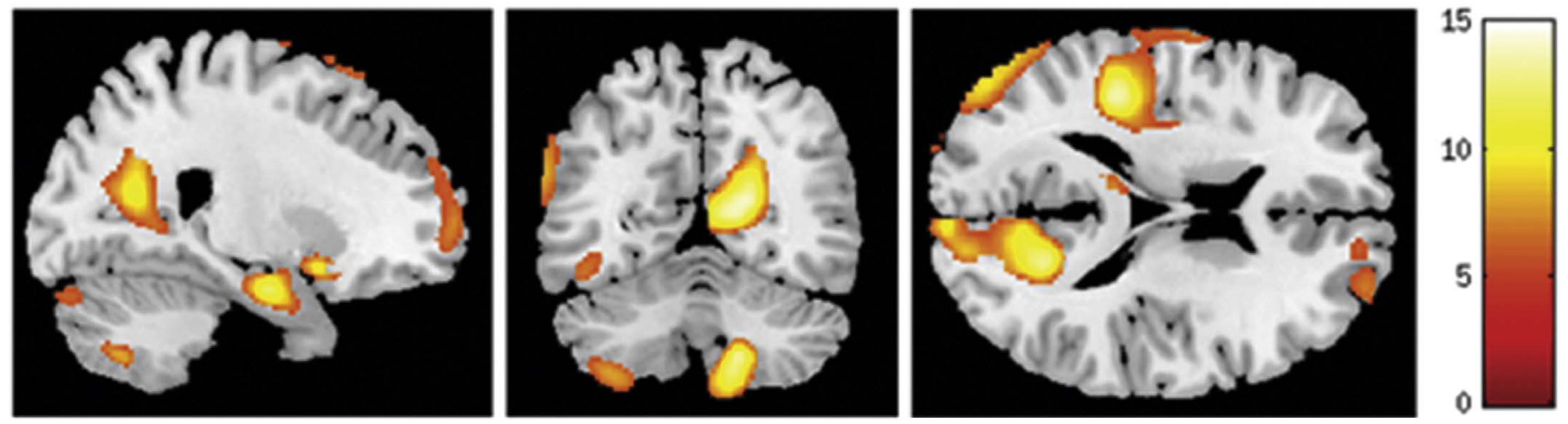

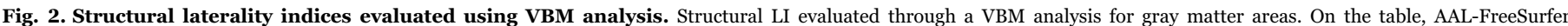

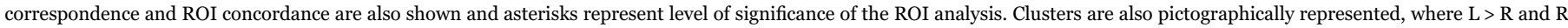

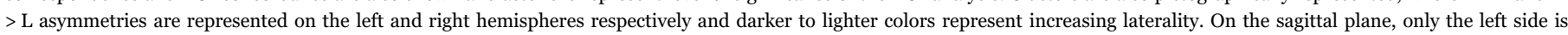
represented. $\mathrm{L}=\mathrm{Left}, \mathrm{R}=\mathrm{Right},{ }^{* *} \mathrm{p}<0.01,{ }^{* * *} \mathrm{p}<0.001, \mathrm{NS}=$ non-significant in Wilcoxon signed rank analysis Bonferroni corrected for 46 comparisons.

SRT-CLTR was correlated with left, but not right, superior frontal gyrus volume in a sex-dependent way (Supplementary Table 4 $\mathrm{p}=0.0017, \quad \beta=-21.6295, \mathrm{R}^{2}=0.7828$ and $\mathrm{p}=0.6173, \quad \beta=-3.9500$, $\mathrm{R}^{2}=0.7125$ respectively). This translated into a positive association between left volume and the score in female subjects (Fig. 5A $\left.\mathrm{p}=0.0219, \mathrm{R}^{2}=0.1047\right)$, which could not be found for the right hemisphere volume (Fig. $5 \mathrm{~A}-\mathrm{p}=0.4702, \mathrm{R}^{2}=0.0105$ ). Relatable findings occurred in the FAS-posterior cingulate associations, which showed a statistically significant education-dependent connection with left, but not right volume (Supplementary Table $4-\mathrm{p}=0.0073, \beta=-21.8486$, $\mathrm{R}^{2}=0.5768$ and $\mathrm{p}=0.3069, \beta=10.2077, \mathrm{R}^{2}=0.5517$, respectively). The post-hoc test showed a similar trend, as left volume was negatively correlated with performance in individuals with more than 4 years of education (Fig. $5 \mathrm{E}-\mathrm{p}=0.0650, \mathrm{R}^{2}=0.1864$ ) while no association was found for the right posterior cingulate volume (Fig. $5 \mathrm{E}-\mathrm{p}=0.8507$, $\mathrm{R}^{2}=0.0020$ )

The remaining analyses showed no associations between cognitive and volumetric data. In fact, SRT-DR score was not correlated with left or right lateral ventricle volume when considering mediation by either sex (Supplementary Table $4-\mathrm{p}=0.4830, \beta=0.9001, \mathrm{R}^{2}=0.3823$ and $\mathrm{p}=0.4322, \quad \beta=1.1892, \quad \mathrm{R}^{2}=0.3869 \quad$ respectively) or education (Supplementary Table $4-\mathrm{p}=0.3609, \beta=-0.1870, \mathrm{R}^{2}=0.3823$ and $\mathrm{p}=0.2427, \beta=-0.3869, \mathrm{R}^{2}=0.3869$ respectively). Also, thalamus left or right volumes were not associated with stroop-wc score (Supplementary Table $4-\mathrm{p}=0.8366, \beta=45.2554, \mathrm{R}^{2}=0.4834$ and $\mathrm{p}=0.6622, \beta=14.2356, \mathrm{R}^{2}=0.4711$ respectively for sex-mediated data).

\section{Discussion}

In the present study we investigated the association between structural asymmetries and cognitive/mood performance in an aged cohort. We demonstrated that most brain areas present some degree of structural asymmetry in either leftward or rightward directions. These were independent of age, cognitive status, years of formal education or sex (except for the fusiform area). Moreover, we were able to show that structural lateralization of specific areas was associated with memory, attention, verbal fluency and mood. These associations were mostly mediated by sex or education and most curiously, they were dependent on left-right relation but not on the absolute left or right volumes.

\section{Structural asymmetries}

A brain-wide ROI-based MRI approach with semi-automatic segmentation was employed to map brain structural asymmetries. This strategy avoided biases associated with area definition as well as potential issues associated with the left/right definition of voxel homotopy, while creating an easily readable output that facilitates structure-function inferences. Widely recognized asymmetries were found, such as a rightward frontal cortex lateralization (Goldberg et al., 2013; Good et al., 2001; Takao et al., 2011; Watkins et al., 2001) and a bigger left ventricle volume (Toga and Thompson, 2003). Concomitantly, we showed that brain-wide asymmetries were not only very consistent within the population, but also were not affected by age, 

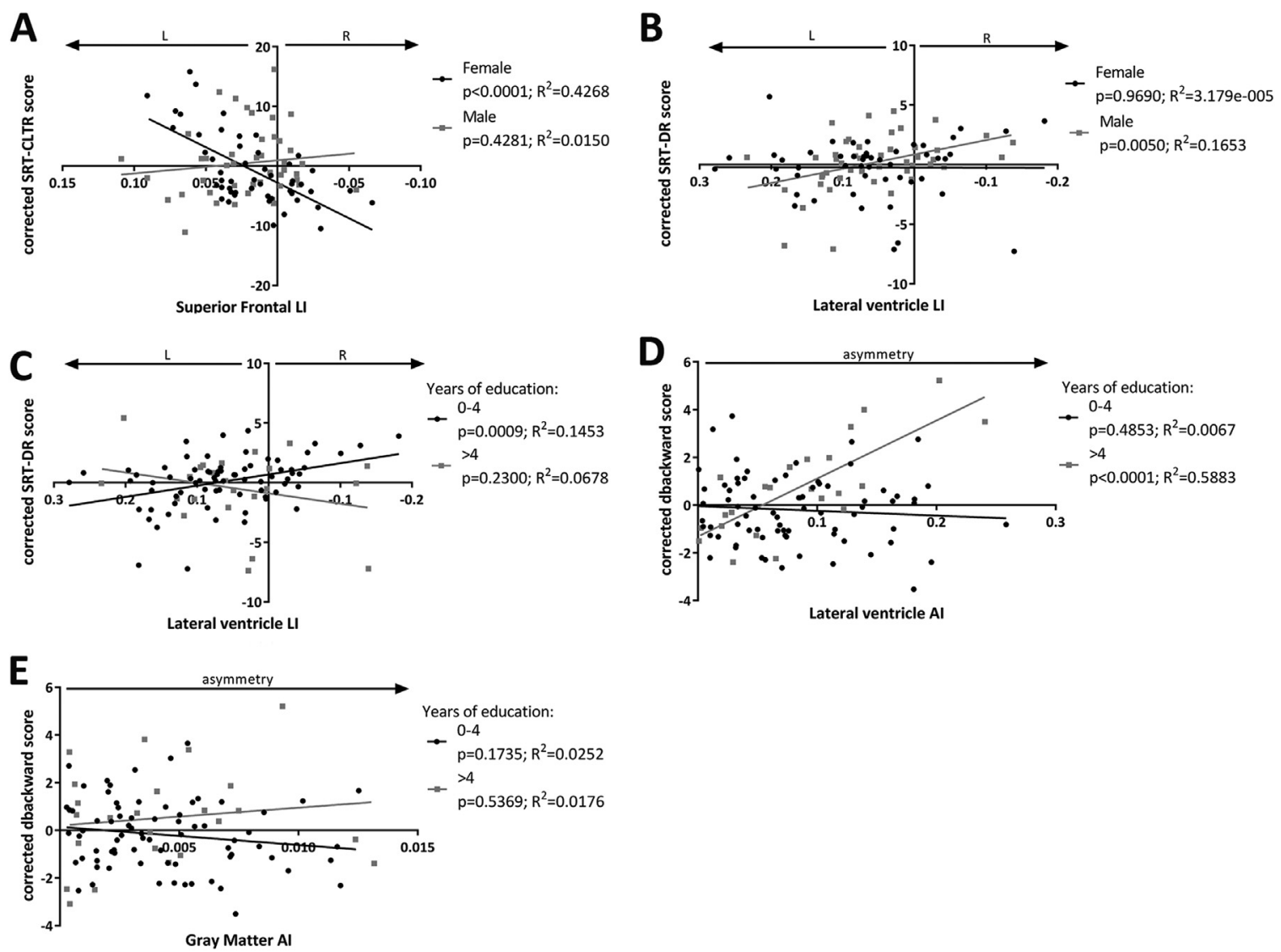

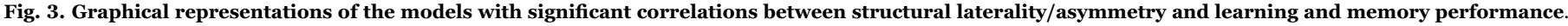

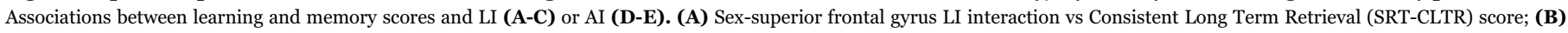

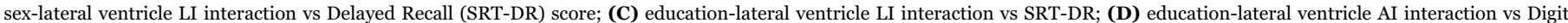

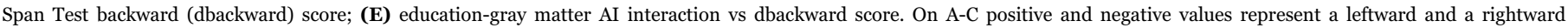

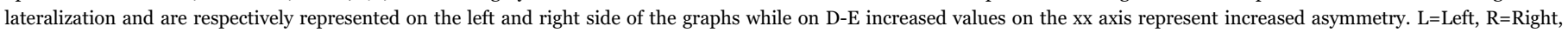
$\mathrm{LI}=$ laterality index, $\mathrm{AI}=$ asymmetry index.

education, cognitive status or sex (except for the fusiform gyrus). These results were largely replicated in the VBM analysis, further validating our approach.

A similar distribution of morphological asymmetries was observed in a previous ROI study, despite differences in the population analyzed (39 adults; age range: 19-40 years old) (Goldberg et al., 2013). Concordance between the latter and our study seems to be higher in lateral rather than medial areas. Moreover, the proportion of asymmetries found in our study is higher, which may be related with differences in the segmentation process or with intrinsic characteristics of the evaluated population. Despite technical and sampling differences, other studies have reported comparable asymmetries such as leftward lateralization in the superior temporal gyrus (Good et al., 2001; Luders et al., 2006; Lyttelton et al., 2009), supramarginal gyrus (Lyttelton et al., 2009), putamen (Cherbuin et al., 2010; Okada et al., 2016; Wyciszkiewicz and Pawlak, 2014), pallidum (Cherbuin et al., 2010; Wyciszkiewicz and Pawlak, 2014) and lateral ventricle (Cherbuin et al., 2010; Okada et al., 2016); or a rightward lateralization of the anterior occipital cortex (Good et al., 2001; Luders et al., 2006; Lyttelton et al., 2009), frontal pole (Watkins et al., 2001), middle frontal gyrus (Watkins et al., 2001), inferior frontal gyrus (Luders et al., 2006; Lyttelton et al., 2009), caudate (Cherbuin et al., 2010; Wyciszkiewicz and Pawlak, 2014), hippocampus (Cherbuin et al., 2010; Okada et al., 2016) and amygdala (Cherbuin et al., 2010; Okada et al., 2016). However, some studies show opposite results (Raz et al., 1997; Takao et al., 2011).

Regarding laterality-influencing factors, no age-dependent differences were found. Despite previous reports describing age-related variations in laterality (Plessen et al., 2014; Zhou et al., 2013) the small age range of our population can largely explain its absence in our study. Additionally, our cohort showed no sexual dimorphism, except in the fusiform gyrus. This area presents functional hemispheric specialization for facial recognition (Ma and Han, 2012), which is known to be sex-dependent (Loven et al., 2014). Other brain-wide studies failed to find overall sex differences (Goldberg et al., 2013; Takao et al., 2011). Others, however, found slight differences on cortical thickness (Luders et al., 2006; Plessen et al., 2014) or VBMmeasured asymmetries between male and female subjects (Good et al., 2001). Of note, to speculate that the post-menopausal state of the women included in our study may alter gender differences on brain structure and mitigate those differences (Eberling et al., 2004; Fukuta et al., 2013).

\section{Cognitive and mood correlates}

Laterality/asymmetry-cognition correlates were found in regards with learning, memory, response inhibition/cognitive flexibility, verbal fluency and mood. Importantly, these laterality associations could only be partially explained by the absolute left (or right) ROI volume and thus the left-right balance seems to be a main contributor in the established models. In summary, the superior frontal gyrus laterality showed a sex-mediated correlation with learning and memory (SRTCLTR), posterior cingulate left-right balance was related with verbal fluency (FAS) in an education-mediated fashion and insula asymmetry was found to be associated with mood (GDS). Moreover, general cortical gray matter asymmetry had a correlation with working memory 


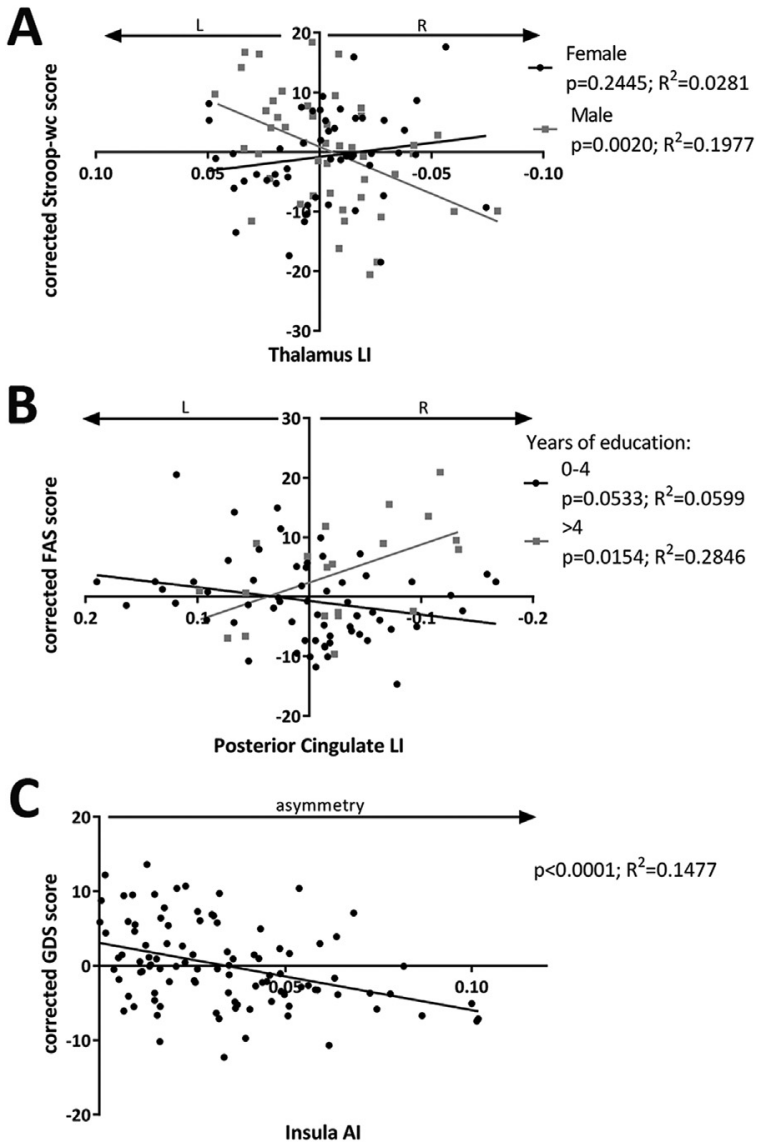

Fig. 4. Graphical representations of the models with significant correlations between structural laterality/asymmetry and cognitive and mood evaluations. Associations between cognitive scores and LI (A-B) and mood score and AI (C). (A) Sex-thalamus LI interaction vs Stroop-words/colors (Stroop-wc) score; (B) education-posterior cingulate LI interaction vs Controlled Oral Word Association F-A-S (FAS) score; (C) Insula AI vs Geriatric Depression Scale (GDS). On A-B positive and negative values represent leftward and rightward lateralization and are respectively represented on the left and right side of the graphs and on $\mathrm{C}$ increased values on the $\mathrm{xx}$ axis represent increased asymmetry. $\mathrm{L}=\mathrm{Left}, \mathrm{R}=\mathrm{Right}$, $\mathrm{LI}=$ laterality index, $\mathrm{AI}=$ asymmetry index.

(dbackward) that was mediated by education.

The PFC has a well-established role in working memory and sexspecific functioning has been shown (Goldstein et al., 2005). The superior frontal gyrus, in particular, seems to be involved in the performance of high (but not low) load working memory tasks (Rypma et al., 1999). Herein, we have shown a female-specific association between a leftward volumetric lateralization of this region and an improved performance in SRT-CLTR, which is partially (although not completely) explained by the left volume-score correlation. In fact, du Boisgueheneuc et al. (2006) have demonstrated that, in a slightly female-enriched population (5:3), left superior frontal gyrus lesion induces working memory deficits in the N-Back task.

The function of the posterior cingulate cortex has not yet been fully elucidated. However, its involvement in self-appraisal tasks has been described for both healthy and cognitively impaired subjects (Ries et al., 2006) and it seems to be involved in verbal fluency (Costafreda et al., 2011). A lateralized effect of posterior cingulate cortex volume in verbal fluency performance was, to the best of our knowledge, never reported and we may hypothesize that this is due to the mediation of education in this correlation, in which left volume seems to play a critical role.

We show a striking association between (side-independent) structural asymmetry of the insula and mood; i.e. irrespective of the direction, increased asymmetry was associated with lower GDS scores. Insular association with depressive symptoms is extensively described.
In fact, left insular cortex volume is decreased in depressive patients, when comparing with healthy controls (Hatton et al., 2012; SorianoMas et al., 2011; Takahashi et al., 2010) and left and right volume reduction is found in depressive patients with suicide attempts (Hwang et al., 2010). The asymmetric involvement of this area in mood processing is still not fully understood. However, a meta-analysis of neural correlates of depression showed left deactivation of the insula in patients when comparing with healthy subjects, while treatment with antidepressants showed no effects on the left, but decreased activation of the right insula (Fitzgerald et al., 2008). Even though none of these authors explored the lateralized effects of their findings and here the assessment concerns depressive mood and not symptomatology, results seem to be in accordance with ours, showing an importance of insular asymmetry for depressive mood.

Interestingly, besides the above-mentioned cortical area-specific associations, general gray matter asymmetry also seems to play a role in cognition. In agreement with the present data, Savic (2014) have previously reported a $\mathrm{R}>\mathrm{L}$ gray matter hemispheric lateralization. Gray matter volume has also been associated with cognitive profiles such as set-shifting (Tsutsumimoto et al., 2015), memory, mental flexibility and speed abilities (Steffener et al., 2013). However, to the best of our knowledge, this is the first description of an association between gray matter asymmetry and working memory score.

Subcortically, only thalamus laterality showed an association with cognition. This region has well-known functions in attention and executive function and decreased cingulo-thalamic connectivity has been associated with worse Stroop interference score (Wagner et al., 2013). Here, a correlation between this area's laterality and Stroop score was not unexpected. Moreover, right-left thalamic imbalances have been linked with language (Ojemann, 1977), memory (Hugdahl and Wester, 1997; Ojemann, 1977; Van der Werf et al., 2003) and complex speeded processing (Van der Werf et al., 2003). We further describe a sex-mediated association between thalamus laterality and the most demanding task of the Stroop test - words/colors -, in which $\mathrm{L}>\mathrm{R}$ volume in men was associated with better performance. Although similar sex mediations were not yet described, sexual dimorphisms of the thalamus were previously reported (Menzler et al., 2011) and, importantly, left and right volumes could not explain this association.

Lateral ventricle enlargement and increase of its leftward asymmetry have been thoroughly correlated with aging (Berardi et al., 1997; Coffey et al., 1998; Fjell et al., 2009; Long et al., 2012) and neurodegenerative diseases such as Alzheimer's (Apostolova et al., 2012; Fjell et al., 2009). Here a leftward lateralization is also noted. Despite this, we also determined that rightward laterality of this area was associated with better delayed recall performance in male and lower educated subjects and importantly, this was exclusively due to left-right volume balance, as individual volumes did not impact the score. On the other hand, higher educated individuals benefited from a more asymmetrical lateral ventricle in the dbackward test. Memoryventricle laterality correlates had been previously reported by Berardi et al. (1997) as elderly (but not in young) subjects, showed an association between laterality of the lateral ventricle and discrepancy between verbal and face memory. We hypothesize that ventricular enlargement is associated with atrophy of the surrounding areas and/ or eventually with reduction of neurogenesis in the sub-ventricular zone and that the asymmetric evolution of this process leads to the described cognitive outcomes.

\section{Conclusions}

As brain asymmetries evolve with age (Plessen et al., 2014; Zhou et al., 2013), it is relevant to explore possible associations between laterality and cognitive performance. Our results show ubiquitous cerebral volumetric asymmetries in the older brain, some of which associated with cognitive performance and mood classification. Interestingly, in some cases a preferred left/right direction is noted, 

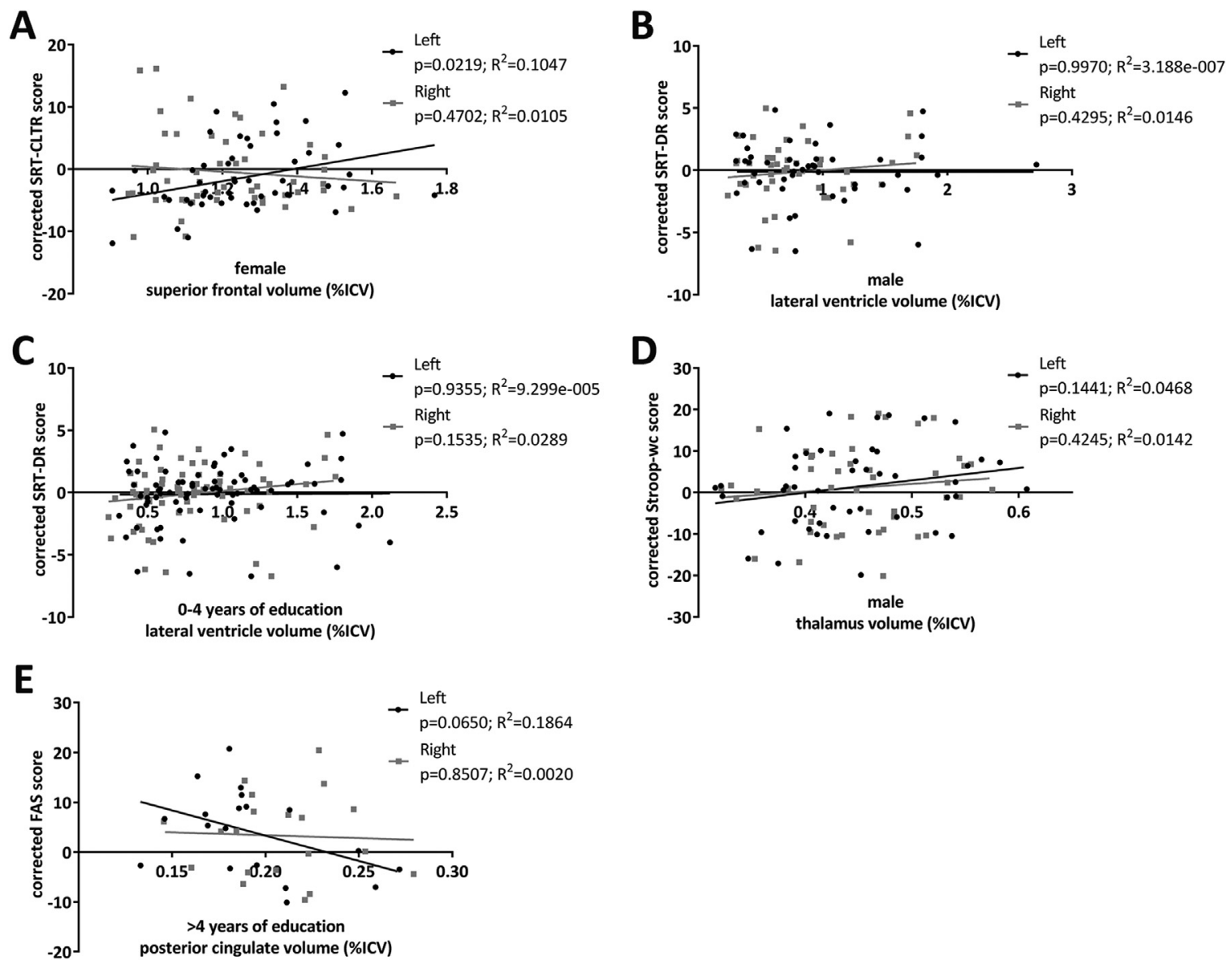

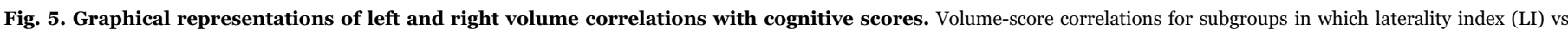

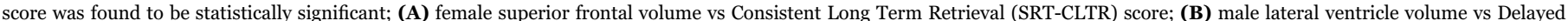

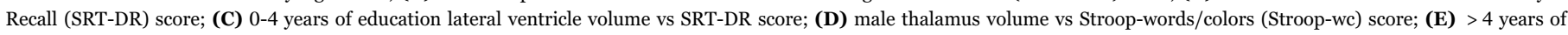
education posterior cingulate volume vs Controlled Oral Word Association F-A-S (FAS) score. All volumes are depicted as percent of intracranial volume (ICV).

while in others the associations occurred without a preferred direction. In addition, in the dbackward task we observed an association with cortical gray matter asymmetry probably as a result of the involvement of a wide network in this type of processes. Despite well described agedependent cortical atrophy (Hedden and Gabrieli, 2004), we were also able to demonstrate that directional (laterality) associations are mostly due to a left-right balance rather than to individual right or left volumes. Finally, redundancy (ROI vs VBM) and analysis stringency - all results have been corrected for multiple comparisons - enabled us to withdraw solid conclusions about the particularities of the aged brain. Our results point to the importance of both left/right and sideindependent structural balance for neuropsychological performance. Further studies regarding functional asymmetries, as well as age differences are needed to better understand the lateralization of cognitive processes.

\section{Acknowledgements}

This work was supported by the European Commission (FP7): "SwitchBox" [contract HEALTH-F2-2010-259772] and Portuguese North Regional Operational Program (ON.2 - O Novo Norte) under the National Strategic Reference Framework (QREN), through the European Regional Development Fund (FEDER) - PM and NCS; Fundação para a Ciência e a Tecnologia (FCT) [grant numbers $\mathrm{SFRH} / \mathrm{BD} / 52291 / 2013$ to $\mathrm{ME}$ via Inter-University Doctoral Programme in Ageing and Chronic Disease (PhDOC), SFRH/BPD/ 80118/2011 to HA and SFRH/BD/90078/2012 to TCC]; and FCT/ MEC and ON.2 - ONOVONORTE - North Portugal Regional
Operational Programme 2007/2013, of the National Strategic Reference Framework (NSRF) 2007/2013, through FEDER [project FCTANR/NEU-OSD/0258/2012 to RM].

\section{Appendix A. Supporting information}

Supplementary data associated with this article can be found in the online version at doi:10.1016/j.neuroimage.2017.03.040.

\section{References}

Ahumada-Galleguillos, P., Lemus, C.G., Diaz, E., Osorio-Reich, M., Hartel, S., Concha, M.L., 2017. Directional asymmetry in the volume of the human habenula. Brain Struct. Funct., (In press).

Apostolova, L.G., Green, A.E., Babakchanian, S., Hwang, K.S., Chou, Y.Y., Toga, A.W Thompson, P.M., 2012. Hippocampal atrophy and ventricular enlargement in normal aging, mild cognitive impairment (MCI), and Alzheimer Disease. Alzheimer Dis. Assoc. Disord. 26, 17-27.

Berardi, A., Haxby, J.V., De Carli, C., Schapiro, M.B., 1997. Face and word memory differences are related to patterns of right and left lateral ventricle size in healthy aging. J. Gerontol. B Psychol. Sci. Soc. Sci. 52b, P54-61.

Busch, R.M., Chapin, J.S., 2008. Review of normative data for common screening measures used to evaluate cognitive functioning in elderly individuals. Clin. Neuropsychol. 22, 620-650.

Buschke, H., Sliwinski, M., Kuslansky, G., Lipton, R.B., 1995. Aging, encoding specificity, and memory change in the Double Memory Test. J. Int. Neuropsychol. Soc. 1, 483-493.

Cabeza, R., Anderson, N.D., Locantore, J.K., McIntosh, A.R., 2002. Aging gracefully: compensatory brain activity in high-performing older adults. NeuroImage 17, 1394-1402.

Chance, S.A., Sawyer, E.K., Clover, L.M., Wicinski, B., Hof, P.R., Crow, T.J., 2013. Hemispheric asymmetry in the fusiform gyrus distinguishes Homo sapiens from chimpanzees. Brain Struct. Funct. 218, 1391-1405. 
Cherbuin, N., Reglade-Meslin, C., Kumar, R., Sachdev, P., Anstey, K.J., 2010. Mild cognitive disorders are associated with different patterns of brain asymmetry than normal aging: the PATH through life study. Front. Psychiatry 1, 11.

Coffey, C.E., Lucke, J.F., Saxton, J.A., Ratcliff, G., Unitas, L.J., Billig, B., Bryan, R.N., 1998. Sex differences in brain aging: a quantitative magnetic resonance imaging study. Arch. Neurol. 55, 169-179.

Concha, M.L., Bianco, I.H., Wilson, S.W., 2012. Encoding asymmetry within neural circuits. Nat. Rev. Neurosci. 13, 832-843.

Conti, E., Calderoni, S., Gaglianese, A., Pannek, K., Mazzotti, S., Rose, S., Scelfo, D., Tosetti, M., Muratori, F., Cioni, G., Guzzetta, A., 2016. Lateralization of brain networks and clinical severity in toddlers with autism spectrum disorder: a HARDI diffusion MRI study. Autism Res. 9, 382-392.

Costa, P.S., Santos, N.C., Cunha, P., Palha, J.A., Sousa, N., 2013. The use of bayesian latent class cluster models to classify patterns of cognitive performance in healthy ageing. PLoS One 8, e71940.

Costafreda, S.G., Fu, C.H., Picchioni, M., Toulopoulou, T., McDonald, C., Kravariti, E., Walshe, M., Prata, D., Murray, R.M., McGuire, P.K., 2011. Pattern of neural responses to verbal fluency shows diagnostic specificity for schizophrenia and bipolar disorder. BMC Psychiatry 11, 18.

Dang, L.C., Samanez-Larkin, G.R., Young, J.S., Cowan, R.L., Kessler, R.M., Zald, D.H., 2016. Caudate asymmetry is related to attentional impulsivity and an objective measure of ADHD-like attentional problems in healthy adults. Brain Struct. Funct. $221,277-286$.

Desikan, R.S., Segonne, F., Fischl, B., Quinn, B.T., Dickerson, B.C., Blacker, D., Buckner, R.L., Dale, A.M., Maguire, R.P., Hyman, B.T., Albert, M.S., Killiany, R.J., 2006. An automated labeling system for subdividing the human cerebral cortex on MRI scans into gyral based regions of interest. NeuroImage 31, 968-980.

Destrieux, C., Fischl, B., Dale, A., Halgren, E., 2010. Automatic parcellation of human cortical gyri and sulci using standard anatomical nomenclature. NeuroImage 53, $1-15$.

du Boisgueheneuc, F., Levy, R., Volle, E., Seassau, M., Duffau, H., Kinkingnehun, S., Samson, Y., Zhang, S., Dubois, B., 2006. Functions of the left superior frontal gyrus in humans: a lesion study. Brain 129, 3315-3328.

Eberling, J.L., Wu, C., Tong-Turnbeaugh, R., Jagust, W.J., 2004. Estrogen- and tamoxifen-associated effects on brain structure and function. NeuroImage 21, 364-371.

Eden, A.S., Schreiber, J., Anwander, A., Keuper, K., Laeger, I., Zwanzger, P., Zwitserlood, P., Kugel, H., Dobel, C., 2015. Emotion regulation and trait anxiety are predicted by the microstructure of fibers between amygdala and prefrontal cortex. J. Neurosci. 35, 6020-6027.

Fedorov, A., Beichel, R., Kalpathy-Cramer, J., Finet, J., Fillion-Robin, J., Pujol, S., Bauer, C., Jennings, D., Fennessy, F., Sonka, M., Buatti, J., Aylward, S., Miller, J., Pieper, S., Kikinis, R., 2012. 3D Slicer as an Image Computing Platform for the Quantitative Imaging Network 30. Elsevier, 1323-1341.

Fischl, B., Salat, D.H., Busa, E., Albert, M., Dieterich, M., Haselgrove, C., van der Kouwe, A., Killiany, R., Kennedy, D., Klaveness, S., Montillo, A., Makris, N., Rosen, B., Dale, A.M., 2002. Whole brain segmentation: automated labeling of neuroanatomical structures in the human brain. Neuron 33, 341-355.

Fitzgerald, P.B., Laird, A.R., Maller, J., Daskalakis, Z.J., 2008. A meta-analytic study of changes in brain activation in depression. Hum. Brain Mapp. 29, 683-695.

Fjell, A.M., Walhovd, K.B., Fennema-Notestine, C., McEvoy, L.K., Hagler, D.J., Holland, D., Brewer, J.B., Dale, A.M., 2009. One-year brain atrophy evident in healthy aging. J. Neurosci. 29, 15223-15231.

Fukuta, H., Ito, I., Tateno, A., Nogami, T., Taiji, Y., Arakawa, R., Suhara, T., Asai, K., Okubo, Y., 2013. Effects of menopause on brain structural changes in schizophrenia. Psychiatry Clin. Neurosci. 67, 3-11.

Galaburda, A.M., LeMay, M., Kemper, T.L., Geschwind, N., 1978. Right-left asymmetrics in the brain. Science 199, 852-856.

Glick, S.D., Ross, D.A., Hough, L.B., 1982. Lateral asymmetry of neurotransmitters in human brain. Brain Res. 234, 53-63.

Goldberg, E., Roediger, D., Kucukboyaci, N.E., Carlson, C., Devinsky, O., Kuzniecky, R., Halgren, E., Thesen, T., 2013. Hemispheric asymmetries of cortical volume in the human brain. Cortex 49, 200-210.

Goldstein, J.M., Jerram, M., Poldrack, R., Anagnoson, R., Breiter, H.C., Makris, N., Goodman, J.M., Tsuang, M.T., Seidman, L.J., 2005. Sex differences in prefrontal cortical brain activity during fMRI of auditory verbal working memory. Neuropsychology 19, 509-519.

Good, C.D., Johnsrude, I., Ashburner, J., Henson, R.N., Friston, K.J., Frackowiak, R.S., 2001. Cerebral asymmetry and the effects of sex and handedness on brain structure: a voxel-based morphometric analysis of 465 normal adult human brains. NeuroImage 14, 685-700.

Grigoletto, F., Zappala, G., Anderson, D.W., Lebowitz, B.D., 1999. Norms for the minimental state examination in a healthy population. Neurology 53, 315-320.

Guerreiro, M., Silva, A.P., Botelho, M.A., Leitão, O., Castro-Caldas, A., Garcia, C., 1994. Adaptação à população portuguesa da tradução do Mini Mental State Examination (MMSE). Rev. Port. De. Neurol. 1, 9-10.

Hatton, S.N., Lagopoulos, J., Hermens, D.F., Naismith, S.L., Bennett, M.R., Hickie, I.B., 2012. Correlating anterior insula gray matter volume changes in young people with clinical and neurocognitive outcomes: an MRI study. BMC Psychiatry 12, 45.

Hedden, T., Gabrieli, J.D., 2004. Insights into the ageing mind: a view from cognitive neuroscience. Nat. Rev. Neurosci. 5, 87-96.

Herbert, M.R., Ziegler, D.A., Deutsch, C.K., O'Brien, L.M., Kennedy, D.N., Filipek, P.A., Bakardjiev, A.I., Hodgson, J., Takeoka, M., Makris, N., Caviness, V.S., Jr., 2005. Brain asymmetries in autism and developmental language disorder: a nested wholebrain analysis. Brain 128, 213-226.

Holm, S., 1979. A simple sequentially rejective multiple test procedure. Scand. J. Stat. 6,
$65-70$.

Hugdahl, K., 2011. Hemispheric asymmetry: contributions from brain imaging. Wiley Interdiscip. Rev.: Cogn. Sci. 2, 461-478.

Hugdahl, K., Wester, K., 1997. Lateralized thalamic stimulation: effects on verbal memory. Neuropsychiatry Neuropsychol. Behav. Neurol. 10, 155-161.

Hwang, J.P., Lee, T.W., Tsai, S.J., Chen, T.J., Yang, C.H., Lirng, J.F., Tsai, C.F., 2010 Cortical and subcortical abnormalities in late-onset depression with history of suicide attempts investigated with MRI and voxel-based morphometry. J. Geriatr. Psychiatry Neurol. 23, 171-184.

Jovicich, J., Czanner, S., Han, X., Salat, D., van der Kouwe, A., Quinn, B., Pacheco, J., Albert, M., Killiany, R., Blacker, D., Maguire, P., Rosas, D., Makris, N., Gollub, R., Dale, A., Dickerson, B.C., Fischl, B., 2009. MRI-derived measurements of human subcortical, ventricular and intracranial brain volumes: reliability effects of scan sessions, acquisition sequences, data analyses, scanner upgrade, scanner vendors and field strengths. NeuroImage 46, 177-192.

Kasprian, G., Langs, G., Brugger, P.C., Bittner, M., Weber, M., Arantes, M., Prayer, D., 2011. The prenatal origin of hemispheric asymmetry: an in utero neuroimaging study. Cereb. Cortex 21, 1076-1083.

Keenan, J.P., Thangaraj, V., Halpern, A.R., Schlaug, G., 2001. Absolute pitch and planum temporale. NeuroImage 14, 1402-1408.

Lezak, M., Howieson, D., Loring, D., 2004. Neuropsychological Assessment. Oxford University Press, New York (NY).

Lindell, A.K., Hudry, K., 2013. Atypicalities in cortical structure, handedness, and functional lateralization for language in autism spectrum disorders. Neuropsychol. Rev. 23, 257-270.

Long, X., Liao, W., Jiang, C., Liang, D., Qiu, B., Zhang, L., 2012. Healthy aging: an automatic analysis of global and regional morphological alterations of human brain. Acad. Radiol. 19, 785-793.

Loven, J., Svard, J., Ebner, N.C., Herlitz, A., Fischer, H., 2014. Face gender modulates women's brain activity during face encoding. Soc. Cogn. Affect. Neurosci. 9, 1000-1005.

Luders, E., Narr, K.L., Thompson, P.M., Rex, D.E., Jancke, L., Toga, A.W., 2006. Hemispheric asymmetries in cortical thickness. Cereb. Cortex 16, 1232-1238.

Lyttelton, O.C., Karama, S., Ad-Dab'bagh, Y., Zatorre, R.J., Carbonell, F., Worsley, K., Evans, A.C., 2009. Positional and surface area asymmetry of the human cerebral cortex. NeuroImage 46, 895-903.

Ma, Y., Han, S., 2012. Functional dissociation of the left and right fusiform gyrus in selfface recognition. Hum. Brain Mapp. 33, 2255-2267.

Mechelli, A., Price, C.J., Friston, K.J., Ashburner, J., 2005. Voxel-based morphometry of the human brain: methods and applications. Curr. Med. Imaging Rev. 1, 105-113.

Menzler, K., Belke, M., Wehrmann, E., Krakow, K., Lengler, U., Jansen, A., Hamer, H.M. Oertel, W.H., Rosenow, F., Knake, S., 2011. Men and women are different: diffusion tensor imaging reveals sexual dimorphism in the microstructure of the thalamus, corpus callosum and cingulum. NeuroImage 54, 2557-2562.

Miyata, J., Sasamoto, A., Koelkebeck, K., Hirao, K., Ueda, K., Kawada, R., Fujimoto, S., Tanaka, Y., Kubota, M., Fukuyama, H., Sawamoto, N., Takahashi, H., Murai, T., 2012. Abnormal asymmetry of white matter integrity in schizophrenia revealed by voxel wise diffusion tensor imaging. Hum. Brain Mapp. 33, 1741-1749.

Narr, K., Thompson, P., Sharma, T., Moussai, J., Zoumalan, C., Rayman, J., Toga, A., 2001. Three-dimensional mapping of gyral shape and cortical surface asymmetries in schizophrenia: gender effects. Am. J. Psychiatry 158, 244-255.

Oertel-Knochel, V., Linden, D.E., 2011. Cerebral asymmetry in schizophrenia. Neuroscientist 17, 456-467.

Ojemann, G.A., 1977. Asymmetric function of the thalamus in man. Ann. N. Y. Acad. Sci. 299, 380-396.

Okada, N., Fukunaga, M., Yamashita, F., Koshiyama, D., Yamamori, H., Ohi, K., Yasuda, Y., Fujimoto, M., Watanabe, Y., Yahata, N., Nemoto, K., Hibar, D.P., van Erp, T.G., Fujino, H., Isobe, M., Isomura, S., Natsubori, T., Narita, H., Hashimoto, N., Miyata, J., Koike, S., Takahashi, T., Yamasue, H., Matsuo, K., Onitsuka, T., Iidaka, T., Kawasaki, Y., Yoshimura, R., Watanabe, Y., Suzuki, M., Turner, J.A., Takeda, M., Thompson, P.M., Ozaki, N., Kasai, K., Hashimoto, R., 2016. Abnormal asymmetries in subcortical brain volume in schizophrenia. Mol. Psychiatry 21, 1460-1466.

Oke, A., Keller, R., Mefford, I., Adams, R.N., 1978. Lateralization of norepinephrine in human thalamus. Science 200, 1411-1413.

Park, H.Y., Hwang, J.Y., Jung, W.H., Shin, N.Y., Shim, G., Jang, J.H., Kwon, J.S., 2013. Altered asymmetry of the anterior cingulate cortex in subjects at genetic high risk for psychosis. Schizophr. Res. 150, 512-518.

Peng, Z., Li, G., Shi, F., Shi, C., Yang, Q., Chan, R.C., Shen, D., 2015. Cortical asymmetries in unaffected siblings of patients with obsessive-compulsive disorder. Psychiatry Res. 234, 346-351.

Plessen, K.J., Hugdahl, K., Bansal, R., Hao, X., Peterson, B.S., 2014. Sex, age, and cognitive correlates of asymmetries in thickness of the cortical mantle across the life span. J. Neurosci. 34, 6294-6302.

Raz, N., Gunning, F.M., Head, D., Dupuis, J.H., McQuain, J., Briggs, S.D., Loken, W.J., Thornton, A.E., Acker, J.D., 1997. Selective aging of the human cerebral cortex observed in vivo: differential vulnerability of the prefrontal gray matter. Cereb. Cortex 7, 268-282.

Reuter-Lorenz, P.A., Cappell, K.A., 2008. Neurocognitive aging and the compensation hypothesis. Curr. Dir. Psychol. Sci. 17, 177-182.

Ribolsi, M., Daskalakis, Z.J., Siracusano, A., Koch, G., 2014. Abnormal asymmetry of brain connectivity in schizophrenia. Front. Hum. Neurosci. 8, 1010.

Ribolsi, M., Koch, G., Magni, V., Di Lorenzo, G., Rubino, I.A., Siracusano, A., Centonze, D., 2009. Abnormal brain lateralization and connectivity in schizophrenia. Rev. Neurosci. 20, 61-70.

Ries, M.L., Schmitz, T.W., Kawahara, T.N., Torgerson, B.M., Trivedi, M.A., Johnson, S.C., 2006. Task-dependent posterior cingulate activation in mild cognitive impairment. 
NeuroImage 29, 485-492.

Rogers, L.J., 2014. Asymmetry of brain and behavior in animals: its development function, and human relevance. Genesis 52, 555-571.

Rypma, B., Prabhakaran, V., Desmond, J.E., Glover, G.H., Gabrieli, J.D., 1999. Loaddependent roles of frontal brain regions in the maintenance of working memory. NeuroImage 9, 216-226.

Santos, N.C., Costa, P.S., Cunha, P., Cotter, J., Sampaio, A., Zihl, J., Almeida, O.F., Cerqueira, J.J., Palha, J.A., Sousa, N., 2013. Mood is a key determinant of cognitive performance in community-dwelling older adults: a cross-sectional analysis. Age 35, 1983-1993.

Santos, N.C., Costa, P.S., Cunha, P., Portugal-Nunes, C., Amorim, L., Cotter, J., Cerqueira, J.J., Palha, J.A., Sousa, N., 2014. Clinical, physical and lifestyle variables and relationship with cognition and mood in aging: a cross-sectional analysis of distinct educational groups. Front. Aging Neurosci. 6, 21.

Savic, I., 2014. Asymmetry of cerebral gray and white matter and structural volumes in relation to sex hormones and chromosomes. Front. Neurosci. 8, 329.

Scheibel, A.B., Paul, L.A., Fried, I., Forsythe, A.B., Tomiyasu, U., Wechsler, A., Kao, A. Slotnick, J., 1985. Dendritic organization of the anterior speech area. Exp. Neurol 87, 109-117.

Song, J.W., Mitchell, P.D., Kolasinski, J., Ellen Grant, P., Galaburda, A.M., Takahashi, E., 2015. Asymmetry of white matter pathways in developing human brains. Cereb. Cortex 25, 2883-2893.

Soriano-Mas, C., Hernandez-Ribas, R., Pujol, J., Urretavizcaya, M., Deus, J., Harrison, B.J., Ortiz, H., Lopez-Sola, M., Menchon, J.M., Cardoner, N., 2011. Cross-sectional and longitudinal assessment of structural brain alterations in melancholic depression. Biol. Psychiatry 69, 318-325.

Steffener, J., Brickman, A.M., Habeck, C.G., Salthouse, T.A., Stern, Y., 2013. Cerebral blood flow and gray matter volume covariance patterns of cognition in aging. Hum. Brain Mapp. 34, 3267-3279.

Strauss, E., Sherman, E.M.S., Spreen, O., 2006. A Compendium of Neuropsychological Tests: administration, Norms and Commentary. Oxford University Press, New York (NY).

Sun, T., Walsh, C.A., 2006. Molecular approaches to brain asymmetry and handedness. Nat. Rev. Neurosci. 7, 655-662.

Sun, Y., Chen, Y., Collinson, S.L., Bezerianos, A., Sim, K., 2015. Reduced hemispheric asymmetry of brain anatomical networks is linked to schizophrenia: a connectome study. Cereb. Cortex., (In press).

Takahashi, T., Yucel, M., Lorenzetti, V., Tanino, R., Whittle, S., Suzuki, M., Walterfang,
M., Pantelis, C., Allen, N.B., 2010. Volumetric MRI study of the insular cortex in individuals with current and past major depression. J. Affect. Disord. 121, 231-238.

Takao, H., Abe, O., Yamasue, H., Aoki, S., Sasaki, H., Kasai, K., Yoshioka, N., Ohtomo, K. 2011. Gray and white matter asymmetries in healthy individuals aged 21-29 years: a voxel-based morphometry and diffusion tensor imaging study. Hum. Brain Mapp. $32,1762-1773$.

Toga, A.W., Thompson, P.M., 2003. Mapping brain asymmetry. Nat. Rev. Neurosci. 4 $37-48$.

Tsutsumimoto, K., Makizako, H., Shimada, H., Doi, T., Suzuki, T., 2015. Set-shifting ability is associated with gray matter volume in older people with mild cognitive impairment. Dement Geriatr. Cogn. Disord. Extra 5, 395-403.

Van der Werf, Y.D., Scheltens, P., Lindeboom, J., Witter, M.P., Uylings, H.B.M., Jolles, J., 2003. Deficits of memory, executive functioning and attention following infarction in the thalamus; a study of 22 cases with localised lesions. Neuropsychologia 41, $1330-1344$.

Wagner, G., Koch, K., Schachtzabel, C., Schultz, C.C., Gaser, C., Reichenbach, J.R., Sauer, H., Bar, K.J., Schlosser, R.G., 2013. Structural basis of the fronto-thalamic dysconnectivity in schizophrenia: a combined DCM-VBM study. NeuroImage Clin. 3 , 95-105.

Watanabe, H., Fitting, S., Hussain, M.Z., Kononenko, O., Iatsyshyna, A., Yoshitake, T., Kehr, J., Alkass, K., Druid, H., Wadensten, H., Andren, P.E., Nylander, I., Wedell, D.H., Krishtal, O., Hauser, K.F., Nyberg, F., Karpyak, V.M., Yakovleva, T., Bakalkin, G., 2015. Asymmetry of the endogenous opioid system in the human anterior cingulate: a putative molecular basis for lateralization of emotions and pain. Cereb. Cortex 25, 97-108.

Watkins, K.E., Paus, T., Lerch, J.P., Zijdenbos, A., Collins, D.L., Neelin, P., Taylor, J., Worsley, K.J., Evans, A.C., 2001. Structural asymmetries in the human brain: a voxel-based statistical analysis of 142 MRI scans. Cereb. Cortex 11, 868-877.

Wechsler, D., 1997. Wechsler Adult Intelligence Scale (WAIS-III). Harcourt Assessment, San Antonio.

Wyciszkiewicz, A., Pawlak, M.A., 2014. Basal Ganglia Volumes: mr-derived reference ranges and lateralization indices for children and young adults. Neuroradiol. J 27, $595-612$.

Yesavage, J.A., Brink, T.L., Rose, T.L., Lum, O., Huang, V., Adey, M., Leirer, V.O., 1982 Development and validation of a geriatric depression screening scale: a preliminary report. J. Psychiatr. Res. 17, 37-49.

Zhou, D., Lebel, C., Evans, A., Beaulieu, C., 2013. Cortical thickness asymmetry from childhood to older adulthood. NeuroImage 83, 66-74. 